Tropical Journal of Pharmaceutical Research April 2018; 17 (4): 701-707

ISSN: $1596-5996$ (print); 1596-9827 (electronic)

(C) Pharmacotherapy Group, Faculty of Pharmacy, University of Benin, Benin City, 300001 Nigeria.

Available online at http://www.tjpr.org

Original Research Article

http://dx.doi.org/10.4314/tjpr.v17i4.20

\title{
Impact of Qualification Framework in United Arab Emirates: A case study of Dubai Pharmacy College undergraduate curriculum
}

\author{
Eman Abu-Gharbieh ${ }^{1,2}$, Sabeena Salam ${ }^{3}$, Saeed A Khan ${ }^{4}$ \\ ${ }^{1}$ Department of Clinical Sciences, College of Medicine, University of Sharjah, ${ }^{2}$ Department of Pharmacology and Toxicology, \\ Dubai Pharmacy College, United Arab Emirates, ${ }^{3}$ Institution Effectiveness Unit, Dubai Pharmacy College, United Arab \\ Emirates, ${ }^{4}$ Department Pharmaceutical Chemistry and Natural Products, Dubai Pharmacy College, Dubai, United Arab \\ Emirates
}

*For correspondence: Email: eabugharbieh@sharjah.ac.ae; Tel: +971 65057289

Sent for review: 13 December 2017

Revised accepted: 17 March 2018

\begin{abstract}
Purpose: To examine the impact of applying Qualifications Framework Emirates (QFE) on the undergraduate Bachelor of Pharmacy (BPharm) curriculum in the United Arab Emirates (UAE) context. Method: Curriculum developers (faculty and other stakeholders) have selected appropriate teaching, learning and assessment strategies for their course/s according to the level descriptors defined by the QFE. Such level descriptors serve as a common platform to support national and international accreditation requirements. In order to align the BPharm curriculum with QFE, an outcomes-based approach had been adopted.

Results: The program benefited in many aspects, particularly, in providing a frame of reference, enabling the offered qualification to be described and compared with similar programs, providing a baseline to compare UAE qualifications with other national and/or international ones, recognising the achievement in learning with different complexity levels. Other benefits include enabling the recognition of prior learning, identifying the learning outcomes needed for new qualifications, facilitating alignment and integration of the quality of educational and experiential outcomes with economic and social development and improving transparency of the individual qualifications through learning outcomes mapping.

Conclusion: Application of QFE to BPharm curriculum at Dubai Pharmacy College ensures a systematic approach in designing and implementing the curriculum, and awarding a principal qualification, which in turn are necessary for effective quality assurance.
\end{abstract}

Keywords: Qualifications Framework Emirates (QFE), Pharmacy curriculum, Outcome-based education, Quality assurance, Competencies

\begin{abstract}
This is an Open Access article that uses a funding model which does not charge readers or their institutions for access and distributed under the terms of the Creative Commons Attribution License (http://creativecommons.org/licenses/by/4.0) and the Budapest Open Access Initiative (http://www.budapestopenaccessinitiative.org/read), which permit unrestricted use, distribution, and reproduction in any medium, provided the original work is properly credited.

Tropical Journal of Pharmaceutical Research is indexed by Science Citation Index (SciSearch), Scopus, International Pharmaceutical Abstract, Chemical Abstracts, Embase, Index Copernicus, EBSCO, African Index Medicus, JournalSeek, Journal Citation Reports/Science Edition, Directory of Open Access Journals (DOAJ), African Journal Online, Bioline International, Open-J-Gate and Pharmacy Abstracts
\end{abstract}

\section{INTRODUCTION}

The last decade has seen a dramatic increase in the number of countries adopting Qualification
Framework (QF) [1]. Countries developed their national qualification framework mostly to relate to international systems, and to participate within globalized labour markets [1]. In United Arab 
Emirates, there is a vital need for human resources development of both citizens and residents. The country addressed the shortage of emerging skills and gaps by expansion of labour market through proper education and training, and developing national policies to ameliorate financial, social and personal competitiveness $[2,3]$. The national framework of qualifications, termed the "Qualifications Framework for the Emirates" QFEmirates, was launched in 2012 by the National Qualifications Authority (NQA) of UAE to bring consistency to the award degree certification system in the country. QFEmirates is designed to be the single structure and reference point through which all qualifications in a country can be compared nationally and internationally [3]. QFEmirates is based on three main features; number of levels, range of learning outcomes at each level and a qualification structure[3]. Each level represents hierarchy of relative difficulty and depth of the qualifications from the most basic (level 1) to the most complex (level 10 doctorate).

Each level is defined by a number of learning outcomes that are described in terms of three domains of knowledge, skills and competencies[3]. Accordingly, achieving LOs successfully for each course in a program ensures the eligibility of the learner to be awarded the relevant qualification. In fact, designing programs based on qualifications framework makes it easier for international alignments, and can facilitate mobility of individual qualification holders [3].

Before the implementation of QF Emirates, research conducted in the UAE has highlighted on the key facts such as discontinuity between curriculum development and delivery and lack of uniformly recognized system to monitor and evaluate the quality of content delivery at different levels of education [4]. The QFEmirates stipulates benchmarks for each qualification level, e.g., level 7 for a Bachelor's degree, level 9 for Master's, and level 10 for Doctorate [5]. The handbook specifies uniform standards concerning content, skills, and features of competence to be achieved at each level across institutions in the country [5].

As a case, Dubai Pharmacy College (DPC), the first pharmacy college in the Gulf, has experienced rapid changes. DPC implemented the QFEmirates standards on all its educational programs; Bachelor of Pharmacy (BPharm) and Master of Pharmacy (MPharm) curricula through several stages. The aim of this paper is to discuss the impact of applying QFE (Qualifications Framework Emirates) on the undergraduate Bachelor of Pharmacy (BPharm) curriculum as a case study.

\section{METHODS}

\section{Stages of implementation}

\section{Top-down approach for program goals and objectives}

Today's globalized terrain aims to pledge students into the international learning environment that is moving towards an outcomebased education. There was a felt need to revise and restructure the BPharm Program goals and objectives. To meet this, both national and international professional competencies requirements [6-10], the stated mission-vision of the college [11], level 7 descriptors and strands specified by QFEmirates [3] were considered.

Since UAE lacks an independent professional body for pharmacy practice[12], formulating skills and competencies goals were a daunting task for a single point of reference. Thus, pharmacists' professional code of conduct defined by Ministry of Health [9], Abu-Dhabi Health Authority (HAAD)[8] and Dubai Health Authority (DHA) were used as guidelines to meet the expectations of the labour market for both community and hospital pharmacy practices. On the other hand, although significant pharmaceutical manufacturing in the UAE started in early 1980s [12], the skills and competencies needed for the sector are not clearly defined.

To address these challenges, an Advisory Board comprising of stakeholders from hospitals, pharmaceutical manufacturers, community pharmacy and alumni played significant roles in identifying skills and competencies necessary for being a competent pharmacist. For example, the concept adapted by World Health Organization (WHO) of "Seven star pharmacists"[13] had been stressed upon. The BPharm program outcome reflects such features as lifelong learner, leader, communicator, decision maker, caregiver, manager and teacher. At that point, a task force named "Program Review and Assessment Committee (PRAC)" was formed. It comprised the Dean, Chief Academic Officer, Graduate Program Director, representative from each Department and Head of Institution Effectiveness Office at Dubai Pharmacy College. Based on the inputs, the formulated program goals clearly focused on knowledge acquisition, skills development and competency achievement.

Benchmarking with other similar national and international programs was another resource for 
formulating appropriate program's goals and objectives. Thus, standards of Accreditation Council for Pharmacy Education (ACPE) were used as a guiding reference to classify the core requirements into four domains, namely Basic Sciences, Basic Biomedical Sciences, Pharmaceutical Sciences and Clinical Sciences.

\section{Bottom-up approach for course learning outcomes}

Traditionally, pharmacy education in various Middle-Eastern countries such as Gulf Cooperation Council countries as well as Egypt, Iraq, Jordan, Lebanon, Palestine, Syria and Yemen followed mainly a teacher- centric approach and focused more on knowledge than on core life skills which are mandatory components of career enhancement [14]. In the evolving process of educational reform towards student-centric and outcome-based approaches, we believe that each course is considered as a significant 'building block' which adds up to an effective program structure.

Bloom's Taxonomy described in Qualifications Framework Emirates Handbook 2012 provided an enabling mechanism to classify learning outcomes that educators set for learners with increasing levels of complexity in cognitive activity and function [3]. The BPharm Program in DPC is composed of 60 courses in addition to Professional Practice Experience in various workplaces like community pharmacies, pharmaceutical industries and hospitals. The learning outcomes of each course were defined and associated with clear teaching/learning pedagogy and assessment criteria. The courses are classified into three major categories namelygeneral education, core requirements, and electives. Each course was mapped to the program outcomes and ranked according to its level and strength of contribution using the scores 1, 2 and 3 for weak/no, moderate and full contributions respectively as shown in Table 1.

During the implementation phase, communication on teaching, learning and assessment strategies was channelled through the Chief Academic Officer. The Dean ensured stakeholders involvement through dialogues between chairs, faculty, alumni and employers. Accordingly, at the program level in DPC, PRAC disseminated the formulated program goal and objectives to each department. While at departmental levels, mission statements and objectives were established.

Multidimensional revision for each course was undertaken. Firstly, several aspects were taken into consideration for ensuring its appropriateness - course title, course code, course delivery, classification according to domains, number of credits and contact hours, pre- and/or co-requisites, and course coordinator and assistants - to level 7 of the QFE stated clearly in a course descriptor form [15]. Secondly, course synopsis were revisited and modified, if needed, to be the official description of the course as stated in the college catalogue for prospective students into the BPharm program in Dubai Pharmacy College. Thirdly, Learning Outcomes (LOs) for each course were limited to not more than six outcomes based on international best practices [16]. The action verbs of the LOs were evaluated according to Bloom's

Table 1: Sample of course outcomes mapping against Program Outcomes (PO)

\begin{tabular}{|c|c|c|c|c|c|c|c|c|c|c|}
\hline \multirow{3}{*}{ Course code } & \multicolumn{10}{|c|}{ Program outcomes } \\
\hline & \multicolumn{4}{|c|}{ Knowledge } & \multicolumn{3}{|c|}{ Skills } & \multicolumn{3}{|c|}{ Competencies } \\
\hline & P01 & PO2 & PO3 & PO4 & PO5 & PO6 & PO7 & P08 & PO9 & P010 \\
\hline CP701 & & & & 1 & & & & 1 & 1 & 1 \\
\hline CP702 & & & & 1 & & 1 & & 1 & 1 & \\
\hline CP703 & & & 1 & & 1 & & & & & \\
\hline CP704 & & & 3 & & & & 3 & & 2 & \\
\hline CP705 & & & & 3 & & & & & 2 & \\
\hline CP706 & & & & 2 & & & & 2 & 2 & \\
\hline CP707 & & & & 3 & & 2 & & & 2 & \\
\hline CP708 & & & & & & 3 & 2 & 2 & 2 & 3 \\
\hline CP709 & & & & 3 & & 2 & 3 & 1 & 1 & 2 \\
\hline CP710 & & & & 2 & & 2 & & & & \\
\hline CP711 & & & & 2 & & 2 & 2 & 1 & 2 & \\
\hline CP712 & & & & 3 & & & & & & \\
\hline CP713 & & & & & & & 2 & & 2 & \\
\hline CP714 & & & & & & & 3 & & 2 & \\
\hline Professional Practice Experience- I (PPE1) & & & & & & & & 3 & 3 & 3 \\
\hline Professional Practice Experience-II (PPE2) & & 2 & & & 2 & & & & 3 & \\
\hline Professional Practice Experience- III (PPE3) & & & & & & & & 3 & 3 & 3 \\
\hline
\end{tabular}

Key: 1 = Minor contribution to PO, 2 = Moderate contributions to PO and 3 = Major contributions to PO 
Taxonomy of educational objectives (Knowledge, Comprehension, Application, Analysis, Synthesis and Evaluation) [17].

Then, LOs were aligned with program outcomes to facilitate course - Program Learning Outcomes (PLO) mapping. Fourthly, in the course contents: suitable topics, contact hours, teaching/learning pedagogy, targeted LOs and assessment strategies were specified. Additionally, learning and information resources (Textbooks, other references) were updated according to the Basic Resources for Pharmacy Education recommended by American Association of Colleges of Pharmacy (AACP) [7]. Furthermore, technology supports were identified and listed.

\section{DISCUSSION}

In the UAE, QFE is a paradigm shift in the landscape of Higher Education. Dubai Pharmacy College's commitment to aligning both Bachelor's and Master's programs with the QFE has been a major accomplishment. This paper has attempted to look at the positive impact of QFE with special reference to DPC specific to the bachelor program. The following section examines these aspects in more detail.

\section{Provided a frame of reference}

The establishment of a single framework (QFEmirates) by issuing of a Federal Decree to National Qualifications Authority on the 23 August 2010 has facilitated the program managers of DPC in developing appropriate strategic directions and policies for the educational program and Professional Practice Experience. Of the 10 levels, the Bachelor of pharmaceutical sciences program offered at DPC was pitched at Level 7 described on the $Q F$ Emirates framework [3].

2. Enabled the offered qualification to be described and compared with similar programs

Since all the programs accredited by the Commission of Academic Accreditation (CAA) in the UAE aligned the programs to the specified level provided in the Framework; it provided a basis for comparisons of UAE qualifications with other similar national and international qualifications. Also, QFE helped DPC to review the Bachelor degree of pharmacy educational trends in the region. Furthermore, it helped to define the BPharm curriculum to the expected program and learning outcomes in comparison to other parallel programs in terms of choosing required credit requirements and program duration.

\section{Provided the baseline to compare UAE qualifications with national and international standards}

The 'snowball-effect' of National Qualification Framework with over 100 countries complying with the Framework provides an opportunity for systematic sharing of experiences internationally. In the UAE, QFE brought 'national' order by enforcing the use of common nomenclature and outcomes-based criteria that provided a shared platform to the licensed education providers.

\section{Recognising the achievement in learning with different complexity levels}

An area of concern that emerged during the in house departmental dialogues was how to define student learning - 'the black box'- in measurable terms. In 2012, DPC started focusing on progression in learning by sequencing courselevel learning outcomes according to the level of difficulty to enhance learning outcomes through shared expectations of the NQA. The BPharm program syllabi were revisited to containing comprehensive information about the intended student learning outcomes aligned with the learning pyramid defined by Bloom's taxonomy. Thus, QFEmirates provided the basis for the design of BPharm curriculum, recognizing sequencing of 'learning outcomes' defined in terms of knowledge, skills, and aspects of competence [5].

\section{Enabled inclusion of the Recognition of Prior Learning (RPL)}

In the UAE, it is the QFEmirates that formally brought about a collaborative inquiry practice of Recognition of Prior Learning (RPL). RPL recognizes the entire range of learning from within the workplaces to other informal settings [18]. DPC started assessing knowledge of skills and that has been achieved outside the formal educational context. Learners are awarded credit when they have demonstrated that they have successfully met the learning outcomes and assessment criteria of a course.

\section{Identify learning outcomes essential for new qualifications}

In the UAE, there is no specific national agency accredits providers like in the United States 'Accreditation Council for Pharmacy Education' (ACPE) that was established in 1932 to meet the 
rigorous complexities of higher education profession qualification standards. NQFendorsed framework served as the starting point to map the curricula. Evaluation and accreditation of this program is solely dependent on the general accreditation Standards 2011 [2] and the QFE offers a set of expectations. Dubai Pharmacy College developed a curriculum mapping exercise starting with articulating learning outcomes of the courses offered based on Bloom's taxonomy centred on the QF Emirates booklet [3]. A set of learning outcome statements for each level is called 'Level Descriptors'. They distinguish the levels within a qualifications framework. The Chief Academic Officer, Heads of the Departments and Assessment Coordinators acted as a focal point to develop well-defined learning outcomes based on QFE 'Level Descriptor 7' which formed the foundation for specific BPharm qualification.

Subsequently, QFEmirates design is based on three features: a) number of levels, b) range of learning outcomes described in terms of knowledge, skill and competence for each level, and c) a qualifications structure [3]. As the stakeholders at DPC became familiar with the QFEmirates Handbook 2012, it became the ready reference tool for new qualifications development, assessment, alignment and comparability. It resulted in starting new principal qualifications the 'Master' program. It was easier to define the new qualifications requirements of the Master's Program based on the three features. Centred on salient features of QFE, DPC designed two Master's (level 9) curriculum namely 'Master of Clinical Pharmacy' and 'Master of Pharmaceutical Product Development' and a certification course in Drug Regulatory Affairs that were launched the programs in 2013 after the CAA approval.

\section{Established mechanisms to facilitate alignment and integration of the quality of educational and experiential outcomes with economic and social development}

Work practices are expanding and becoming more complex. This means that the labour market is demanding different ranges of qualifications.

\section{Improved transparency of the individual qualifications through learning outcomes mapping.}

QFE shifted away from learning inputs to learning outcomes. Student Learning Outcomes defines curriculum, assessment and qualifications in terms of what a learner knows, understands and can do as a result of a learning process; this is a critically important shift [3].

Keeping teaching, learning and assessment strategies at the heart of program improvement, the Level Descriptors set the stage with learning outcomes statements that defined levels in the framework of qualifications. The grid provided in Guide to Writing Learning Outcomes at Program and Course Level that Align with QFEmirates guided the faculty members in aligning the existing program and course learning outcomes (LO's) to the QFEmirates strands. The strands describe knowledge and skill and three related features of competence (autonomy and responsibility, role in context, and selfdevelopment) [3]. This guidance in the booklet redefined the task of delivering nationally accredited program offered at DPC.

Importantly, the institution and faculty developed and encompassed a learning outcomes-based approach leading towards transparency and validity providing valuable input for managerial decision making. The Bachelor program's objectives and course descriptions were clearly delineated and published on the college website [10]. Moreover, the reengineered course syllabus contains comprehensive information about the intended student learning outcomes, their alignment with program outcomes that is aligned with the level descriptors defined by $Q F$ Emirates, instructor information, pre-corequisites, course description, appropriate teaching pedagogy, assessment tools, timeline for assessments and topics coverage, in addition to essential text books and other crucial reading materials. QFE is a tool to assure consistency and integrity of qualifications outcomes, a transparent multi-source continuous feedback system across courses and programs is implemented that is funnelled through the recently formed (2013) of Program Review and Assessment Committee (PRAC).

\section{Limitations of the study}

Although QFEmirates can support many policies, it is not a solution to fulfilling all our educational and labour market needs. QFEmirates is built upon people's general awareness about what level of qualification is needed to progress to another qualification or to gain entry into the job market thus making the QFEmirates levels too general as a referencing point. In the long run, specific professional sectors need to develop and define clear-cut level descriptors as a point of reference for professional qualifications.

Additionally, working the way through any National Qualifications Framework is a 
responsibility and challenge for policy makers or program managers. It is easy to find reasons to dismiss the standards. If the skills and competencies specified in the 'level descriptors' are representative of the sector of program offerings, then it may be accepted with less resistance.

\section{CONCLUSION}

Application of QFEmirates increased consistency, transparency, portability and progression for individual qualifications awarded by Dubai Pharmacy College and ensured systematic approach in designing and delivering the curriculum, which in turn are necessary for effective quality assurance.

\section{DECLARATIONS}

\section{Acknowledgement}

The authors wish to thank all faculty and administrative staffs at Dubai Pharmacy College for their efforts and contributions in every step toward the implementation of outcome-basededucation.

\section{Conflict of interest}

No conflict of interest is associated with this work

\section{Contribution of authors}

We declare that this work was done by the authors named in this article and all liabilities pertaining to claims relating to the content of this article will be borne by the authors. All authors contributes equally to prepare this manuscript. Particularly, Eman Abu-Gharbieh was the Chief Academic Officer during the phase of QFEmirates implementation, Mrs. Sabeena Salam is the Head of Institutional Effectiveness Unit and Prof. Saeed A. Khan is the Dean of Dubai Pharmacy Colege.

\section{REFERENCES}

1. Allais S. The implementation and impact of National Qualifications Frameworks: Report of a study in 16 countries. In. International Labour Organization; 2010. [Cited 2018 Feb 10] Available from: http://www.ilo.org/wcmsp5/groups/public/@ed_emp/@if p_skills/documents/meetingdocument/wcms_126589.pd

2. Commission for Academic Accreditation-Ministry of Higher Education and Scientific Research-United Arab Emirates. Standards for Licensure and Accreditation-
2011. [Cited 2016 Mar 10] Available from: https://www.caa.ae/caa/images/standards2011.pdf

3. National Qualifications Authority (NQA): Qualifications Framework Emirates Handbook, 2012 [Cited 2016 Mar 10] Available from: http://www.qualifications.ae/pdf/ QF\%20Handbook_v1b_28_Feb_2012.pdf

4. Sue Parker: Qualifications Framework for the Emirates (QFEmirates). [Cited 2016 Mar 10]. Available from: https://www.caa.ae/caa/.\%5Cimages\%5CQFEmirates_S ueParker.pdf

5. Commission for Academic Accreditation United Arab Emirates. Guide to Writing Learning Outcomes at Program and Course Level that Align with QFEmirates. [Cited 2016 Mar 10] Available from: https://www.caa.ae/caa/images/QFEmirates_Extracts.pd $f$

6. The National Association of Pharmacy Regulatory Authorities. Framework for Assessing Canadian Pharmacists' Competencies at Entry-to-Practice. [Cited 2016 Mar 10]. Available from: http://napra.cal sites/default/files/201708/Framework_for_Assessing_Ca nadian_Pharmacists_Competencies.pdf

7. Pharmaceutical Society of Australia National: Competency Standards Framework for Pharmacists in Australia, 2003 [Cited 2016 Mar 10]. Available from: https://www.psa.org.au/wpfb-file/national-competencystandards-framework-for-pharmacists-in-australia-2016pdf-2mb-pdf

8. Health Authority-Abu Dhabi. Professional Competencies for Pharmacist, 2008 [Cited 2016 Mar 10]. Available from: https://www.haad.ae/HAAD/LinkClick.aspx?filetic ket=2xQugKOuqK0\%3D\&tabid $=819$

9. Ministry of Health: Pharmacists- Professional Code of Conduct, 2011. [Cited 2016 Mar 10]. Available form: http://www.cpd-pharma.ae/phocadownload/MOH-Polic ies-Circulars/MOH-UAE-PHC\%20Code_Conduct_bo ok _eng-\%20Pharmacists\%20chapter.pdf

10. International Pharmaceutical Federation: FIP Education Initiatives, Pharmacy Education Taskforce a Global Competency Framework, 2012. https://www.caa. ae/caa/.\%5Cimages\%5CQFEmirates_SueParker.pdf

11. Dubai Pharmacy College, 2016 [Cited 2016 Mar 10]. Available from: $h t t p s: / / w w w . d p c . e d u$

12. Dameh M. Pharmacy in the United Arab Emirates. South Med Rev 2009; 2: 15-18.

13. Thamby S, Parasuraman S. Seven-star pharmacist concept by World Health Organization. J Young Pharm 2014; 6: 1-3.

14. Kheir N, Zaidan M, Younes H, El Hajj M, Wilbur K, Jewesson PJ. Pharmacy education and practice in 13 Middle Eastern countries. Am J Pharm Educ 2008; 72 : 133.

15. Shersad F, Sheikh H, Aldoori MI, Ahmed MGED, MuscatBaron JM, Abdelmannan D, Hamdy H, Raza STH, Kumar PJ, Bayoumy FA, et al. Proceedings of the 9th Annual Dubai Medical Education Symposium 2015: Dubai, UAE. 30 May 2015. BMC Proc 2016; 10: 2. 
16. Office of Planning and Assessment- Texas Tech University. Writing and assessing course-level expected learning outcomes. [Cited 2018 Feb 10]. Available from: https://www.depts.ttu.edu/opa/resources/docs/Writing_L earning_Outcomes_Handbook3.pdf

17. Anderson LW, Krathwohl DR, Bloom BS. A taxonomy for learning, teaching, and assessing: a revision of Bloom's taxonomy of educational objectives, Complete ed. New York: Longman; 2001.

18. National Qualifications Authority. Recognition of Prior Learning. [Cited 2018 Feb 10] Available from: https://www.nqa.gov.ae/EN/Pages/QFEmirates/Recognit ionPriorLearning.aspx 